\title{
Minimizing Investment Risk of Integrated Rail and Transit-Oriented-Development Projects over Years in a Linear Monocentric City
}

\author{
Ding Liu, ${ }^{1,2}$ Xi Jiang, ${ }^{2}$ Lingyun Meng, ${ }^{2}$ and Ying-En (Ethan) Ge ${ }^{1,2,3}$ \\ ${ }^{1}$ College of Transport \& Communications, Shanghai Maritime University, Shanghai 201306, China \\ ${ }^{2}$ State Key Laboratory of Rail Traffic Control and Safety, Beijing Jiaotong University, Beijing 100044, China \\ ${ }^{3}$ School of Transport \& Logistics, Faculty of Infrastructure Engineering, Dalian University of Technology, Liaoning 116024, China \\ Correspondence should be addressed to Ying-En (Ethan) Ge; yege@shmtu.edu.cn
}

Received 31 May 2016; Accepted 16 August 2016

Academic Editor: Paolo Renna

Copyright (C) 2016 Ding Liu et al. This is an open access article distributed under the Creative Commons Attribution License, which permits unrestricted use, distribution, and reproduction in any medium, provided the original work is properly cited.

\begin{abstract}
Rail and transit-oriented-development (TOD) projects are simultaneously optimized in this paper, with special consideration given to yearly variation and spatial and temporal correlation of population densities. In the proposed model, the objective is to minimize the investment risk of integrated rail and TOD projects with a given required expected return on investment. The investment risk is optimized based on closed-form solutions of the design variables, including rail line length, the number of TOD projects, and the number of housing units in each TOD project. The closed-form solutions are given explicitly under the assumption of social welfare maximization. It is found that underestimation exists for rail and TOD projects without consideration of the correlation of spatial and temporal population densities. TOD projects can greatly improve the return on investment of the rail operator. A numerical example is also presented.
\end{abstract}

\section{Introduction}

1.1. Literature Review and Motivation. The transit-orienteddevelopment (TOD) policy is one alternative approach to the development of rail projects with no requirement on direct financial subsidy from the government. Given this approach, the government may also grant the development rights of the land above underground rail stations or in their neighborhood areas to a private rail operator, in a form of indirect subsidies. The rail operator usually builds and operates a rail project and uses the revenue generated from it to finance the capital cost of it. In other words, rail and TOD projects are developed simultaneously, and TOD projects may be used to subsidize rail projects [1].

TOD projects have been investigated in many previous studies (such as [2-4]). Although TOD has been comprehensively discussed, analytical models for assisting TOD planners are still relatively few [4]. Li et al. [5] proposed a model to investigate the effects of integrated rail and property development projects on the design of rail line services in a linear monocentric city. Their study, however, was conducted in a particular year and the year-on-year investment risks of rail and TOD projects were not fully explored.

The investment analysis of rail and TOD projects should be conducted over a relatively long period (at least a few years). The investment risks of these projects are closely and directly related to travel demand of rail service and population densities in all residential locations, and their variations year on year.

The correlation between spatial and temporal population densities in all residential locations (CPDRL) also affects the investment risk of rail and TOD projects. For instance, more households live in the first TOD project; fewer live in other TOD projects. In other words, negative spatial correlation exists between population densities in the first TOD project and the other TOD projects [6]. The increase of population density in the first year leads to the increase of population density in the second year, and then positive 


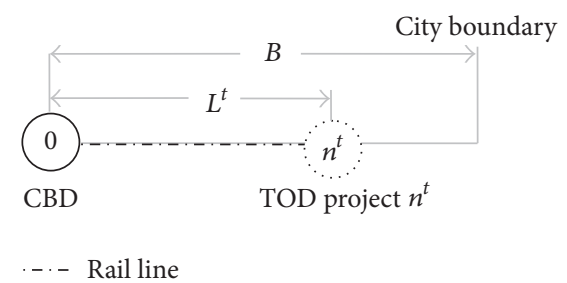

FIGURE 1: Configuration of rail and TOD projects over years in a linear monocentric city.

temporal correlation exists between the first year and the second year, and vice versa.

The investment risk of rail and TOD projects can be measured by standard deviation of return on investment (ROI) of these projects $[7,8]$. The standard deviation of ROI is a function of yearly variation in population density and spatial and temporal correlations of population densities in all residential locations (CPDRL).

In this paper, the rail and TOD projects are optimized simultaneously, with special consideration given to the yearly variation in population density and CPDRL. The proposed model can assist the authorities and/or operators in dealing with the investment risks of rail and TOD projects.

1.2. Problem Statement and Intellectual Merits. As shown in Figure 1, rail and TOD projects are assumed to be developed simultaneously in a linear monocentric city. A rail project is assumed to be built since the beginning of the central business district (CBD). The rail line length in year $t$ is assumed to be $L^{t}\left(0<L^{t} \leq B\right), B$ is the distance between the CBD and the city boundary, the number of TOD projects in year $t$ is represented by $n^{t}, n_{s}^{t}$ denotes the number of underground rail stations in year $t\left(0<n_{s}^{t} \leq N\right.$, where $N$ is a positive integer), and $Y_{i}^{t}\left(\forall i \in\left[1, n^{t}\right], Y_{i}^{t}>0\right)$ is the number of housing units in each TOD project $i$ in year $t$ [9].

Due to the limitation of funds and the limited travel demand at the initial years of the rail and TOD projects, a detailed projects scheme is assumed to be urgently needed. The decision variables include rail line length, the number of TOD projects, and the number of housing units in each TOD project. Since the uncertainties of population densities are considered, that is, yearly variation in population density in each residential location and CPDRL, the above decision variables are stochastic variables in $t$.

The main contribution of this paper includes the following: (1) the synergy between rail and TOD projects over years is considered. (2) The closed-form solutions for the optimal design variables of the rail and TOD projects are given. (3) The effects of spatial and temporal correlations of population densities on the standard deviation of ROI for the rail and TOD projects are explored.

The remainder of this paper is organized as follows. In Section 2, assumptions are presented with some basic considerations of rail and TOD projects. Section 3 proposes an investment risk minimization model constrained by a required expected ROI. A numerical example is used to illustrate the application of the proposed model in Section 4 together with some insightful findings. Section 5 concludes this paper with some suggestions for further investigation. Notations used in this paper are listed and defined in the Appendix.

\section{Preliminaries}

For the sake of exposition, the following assumptions are made.

(A1) All job opportunities are assumed to be supplied in the CBD. Therefore, the residential location-CBD commuting trip is a daily compulsory activity. Households are assumed to be homogenous and minimize the daily disutility. The daily disutility is assumed to be composed of generalized travel cost and daily housing rent. Households are assumed to make residential location choice by tradeoff between generalized travel cost and daily housing rent [5].

(A2) The rail and TOD projects are assumed to be finished on time, and rail service and housing service can be supplied at the end of each period during the design time horizon $[10,11]$.

(A3) The rail operator's objective is the investment risk minimization of rail and TOD projects with a given required expected ROI. This objective can guarantee an enough profit measured in the mean value of ROI, with the least risk measured in the standard deviation of ROI $[7,8]$.

2.1. Investment Risk of Rail and TOD Projects. The investment risk analysis of rail and TOD projects is quite necessary, due to the huge infrastructure investment requirement of rail and TOD projects. ROI is a measure of cash generated or lost due to the investment and may be represented by the cash flow to the investor from the investment, relative to the amount invested. Specifically, it is defined as the ratio of profit (whether realized or unrealized) from an investment to the amount of money invested. Accordingly, the ROI of candidate rail and TOD projects can be calculated by

$$
\mathrm{ROI}_{r+\mathrm{TOD}}=\alpha \mathrm{ROI}_{0}+\sum_{i=1}^{n^{t}} \alpha_{i} \mathrm{ROI}_{i},
$$

where $\mathrm{ROI}_{0}$ represents ROI of the rail project and $\mathrm{ROI}_{i}(\forall i \epsilon$ $\left.\left[1, n^{t}\right]\right)$ represents ROI of TOD project $i$, given by

$$
\begin{aligned}
\mathrm{ROI}_{0} & =\frac{\mathrm{PR}}{\sum_{t=1}^{m}\left(L^{t} C_{r}+n_{s}^{t} C_{s}\right)}, \\
\mathrm{ROI}_{i} & =\frac{\mathrm{PT}_{i}}{\sum_{t=1}^{m} \sum_{j=1}^{n^{t}} Y_{j}^{t} C_{j}},
\end{aligned}
$$

where $\mathrm{PR}$ represents profit from rail project, $\mathrm{PT}_{i}$ represents profit from TOD project $i, L^{t}$ is rail line length in year $t, C_{r}$ is unit fixed construction cost of rail line, $n_{s}^{t}$ is rail station 
number in year $t, C_{s}$ is fixed construction cost of each rail station, $Y_{j}^{t}$ is housing unit in TOD project $j$ in year $t$, and $C_{j}$ is average fixed cost to construct each housing unit in TOD $j$. In terms of (1) and (2), $\mathrm{ROI}_{r+\mathrm{TOD}}$ is a function of the following design variables, including rail line length $L^{t}$, TOD project number $n^{t}$, and housing unit of each TOD project $Y_{j}^{t}$.

$\mathrm{ROI}_{i}\left(\forall i \in\left[0, n^{t}\right]\right)$ is a stochastic variable, which has the mean value of $E\left(\mathrm{ROI}_{i}\right)$ and the standard deviation of $\sigma\left(\mathrm{ROI}_{i}\right)$. The covariance between $\mathrm{ROI}_{i}$ and $\mathrm{ROI}_{j}\left(\forall i, j \in\left[0, n^{t}\right]\right)$ is denoted by $\sigma\left(\mathrm{ROI}_{i}, \mathrm{ROI}_{j}\right)$, which are functions of the covariance between population densities in residential locations around rail stations $i$ and $j$. In terms of (1), $\mathrm{ROI}_{r+\mathrm{TOD}}$ is also a stochastic variable. The mean value of $\mathrm{ROI}_{r+\mathrm{TOD}}$ is denoted by $E\left(\mathrm{ROI}_{r+\mathrm{TOD}}\right)$, and its standard deviation is denoted by $\sigma\left(\mathrm{ROI}_{r+\mathrm{TOD}}\right)$.

Accordingly, $\alpha$ and $\alpha_{i}$ in (1) are the investment proportion on rail project and each TOD project $i$, respectively; namely,

$$
\begin{gathered}
\alpha=\frac{\sum_{t=1}^{m}\left(L^{t} C_{r}+n_{s}^{t} C_{s}\right)}{\sum_{t=1}^{m}\left(L^{t} C_{r}+n_{s}^{t} C_{s}\right)+\sum_{t=1}^{m} \sum_{i=1}^{n^{t}} Y_{i}^{t} C_{i}}, \\
\alpha_{i}=\frac{Y_{i}^{t} C_{i}}{\sum_{t=1}^{m}\left(L^{t} C_{r}+n_{s}^{t} C_{s}\right)+\sum_{t=1}^{m} \sum_{j=1}^{n^{t}} Y_{j}^{t} C_{j}} .
\end{gathered}
$$

2.2. Profit and Social Welfare of Rail and TOD Projects. The profit of the rail project (PR) equals the revenue of fare minus relative cost, expressed as

$$
\mathrm{PR}=\sum_{t=1}^{m} \sum_{i=1}^{n_{s}^{t}}\left(q_{i}^{t, \text { sue }}(f-c)\right)-L^{t} C_{r}-n_{s}^{t} C_{s}
$$

where $q_{i}^{t \text {,sue }}$ is stochastic user equilibrium (SUE) based passenger travel demand of rail station $i$ in year $t, f$ is flat fare of rail service for each passenger, $c$ is variable operation cost for each passenger, $C_{r}$ is unit fixed construction cost of rail line, and $C_{s}$ is fixed construction cost of each rail station.

For the candidate rail and TOD projects, more concerns are focused on the increase of social welfare. Consumer surplus is a component of social welfare. The consumer surplus of the rail project (CSR) is

$$
\mathrm{CSR}=\sum_{i=1}^{n_{s}^{t}}\left(\int_{0}^{q_{i}^{t}}\left(q_{i}^{t}\right)^{-1}(w) \mathrm{d} w-q_{i}^{t} \pi_{i}^{t}\right)=\sum_{i=1}^{n_{s}^{t}} \frac{q_{i}^{t, \text { sue }}}{\theta}
$$

where $q_{i}^{t}$ is passenger travel demand of rail station $i$ in year $t$, $\left(q_{i}^{t}\right)^{-1}$ is its inverse demand function with $\left(q_{i}^{t}\right)^{-1}\left(q_{i}^{t}\right)=\pi_{i}^{t}=$ $(1 / \theta) \ln \left(P_{i}^{t} / q_{i}^{t}\right), \pi_{i}^{t}$ is generalized travel cost of passengers from rail station $i$ to the CBD in year $t, P_{i}^{t}$ is population density around rail station $i$ in year $t$, and $\theta$ is a positive constant in passenger travel demand function. In terms of (4) and (5), the social welfare of the rail project (SWR) is

$$
\begin{aligned}
\mathrm{SWR}= & \mathrm{PR}+\mathrm{CSR} \\
= & \sum_{t=1}^{m} \sum_{i=1}^{n_{s}^{t}}\left(q_{i}^{t, \text { sue }}(f-c)\right)-L^{t} C_{r}-n_{s}^{t} C_{s} \\
& +\sum_{i=1}^{n_{s}^{t}} \frac{q_{i}^{t, \text { sue }}}{\theta} .
\end{aligned}
$$

The profit of TOD project $i\left(\forall i \in\left[1, n^{t}\right]\right)\left(\mathrm{PT}_{i}\right)$ similarly can be calculated by

$$
\mathrm{PT}_{i}=\sum_{j=1}^{m}\left(P_{i}^{j, \text { sue }}\left(r_{i}^{j}-c_{i}\right)-Y_{i}^{j} C_{i}\right)
$$

where $r_{i}^{j}$ is daily housing rent of TOD $i$ in year $j, c_{i}$ is the variable cost to supply housing service for each passenger, $Y_{i}^{j}$ is housing unit in TOD project $i$ in year $j$, and $C_{i}$ is the average fixed cost to construct each housing unit in TOD $i$.

The consumer surplus of TOD project $i\left(\forall i \in\left[1, n^{t}\right]\right)$ $\left(\mathrm{CST}_{i}\right)$ is calculated by

$$
\operatorname{CST}_{i}=\sum_{j=1}^{m}\left(\int_{0}^{P_{i}^{j}}\left(P_{i}^{j}\right)^{-1}(w) \mathrm{d} w-P_{i}^{j} r_{i}^{j}\right)
$$

where $P_{i}^{j}$ is population density of TOD project $i$ in year $j$ and $\left(P_{i}^{j}\right)^{-1}$ is its inverse function, representing households' willingness to pay for housing service of TOD project $i$ in year $j$. Then, the social welfare of TOD projects (SWT) is given by

$$
\begin{gathered}
\mathrm{SWT}=\sum_{i=1}^{n^{t}}\left(\mathrm{CST}_{i}+\mathrm{PT}_{i}\right)=\sum_{i=1}^{n^{t}} \sum_{j=1}^{m}\left(P_{i}^{j, \text { sue }}\left(r_{i}^{j}-c_{i}\right)\right. \\
\left.-Y_{i}^{j} C_{i}+\int_{0}^{P_{i}^{j}}\left(P_{i}^{j}\right)^{-1}(w) \mathrm{d} w-P_{i}^{j} r_{i}^{j}\right) .
\end{gathered}
$$

2.3. Stochastic User Equilibrium (SUE) Condition. In terms of (A1), households are assumed to choose the residential locations to minimize their own disutilities. This disutility is assumed to be composed of two parts: generalized travel cost and daily housing rent; namely,

$$
U_{i}^{t}=\pi_{i}^{t}+r_{i}^{t}+\varepsilon_{i}^{t}, \quad\left(\forall i \in\left[1, n_{s}^{t}\right], t \in[1, m]\right),
$$

where $U_{i}^{t}$ is passenger disutility for residential location around rail station $i$ in year $t, \pi_{i}^{t}$ is the generalized travel cost from rail station $i$ to the CBD in year $t, r_{i}^{t}$ is daily housing rent in residential location around rail station $i$ in year $t$, and $\varepsilon_{i}^{t}$ is the perception error of generalized travel cost.

Both generalized travel cost and daily housing rent are functions of population density in each residential location. 
Regarding generalized travel cost function, the Bureau of Public Roads (BPR) functions are used in the following numerical example. The daily housing rent function should satisfy two basic properties: (1) the daily housing rent should increase while the total demand for housing service increases and (2) the daily housing rent should decrease while the total supply of housing service increases. In this paper, the daily housing rent in TOD project $i$ in year $t, r_{i}^{t}$, is defined as [12]

$$
r_{i}^{t}=\chi_{0}\left(1+\chi_{1} \frac{P_{i}^{t}}{Y_{i}^{t}}\right), \quad\left(\forall i \in\left[1, n^{t}\right], t \in[1, m]\right),
$$

where $\chi_{0}$ is the base daily housing rent in terms of $\mathrm{HKD} / \mathrm{unit}$, $\chi_{1}$ is a positive scalar parameter that represents the sensitivity of daily housing rent on housing supply and demand, and $Y_{i}^{t}$ is the average density of housing units in TOD project $i$. For those residential locations without TOD projects, the housing unit $Y o_{i}\left(i \in\left[1, n_{s}^{t}-n^{t}\right]\right)$ is assumed to be constant over the years in planning horizon. The daily housing rent of other residential locations, $r o_{i}^{t}$, is defined as

$$
\begin{aligned}
r o_{i}^{t}=\chi o_{0}\left(1+\chi o_{1} \frac{P_{i}^{t}}{Y o_{i}}\right) & \\
& \left(i \in\left[1, n_{s}^{t}-n^{t}\right], t \in[1, m]\right),
\end{aligned}
$$

where $\chi o_{0}$ is the base daily housing rent of other residential locations in terms of $\mathrm{HKD} /$ unit and $\chi o_{1}$ is a positive scalar parameter of other residential locations which represents the sensitivity of daily housing rent on housing supply and demand.

According to the conservation law of population, we have

$$
\sum_{i=1}^{n_{s}^{t}} P_{i}^{t}=P_{0}^{t}
$$

where $P_{i}^{t}$ is population density in residential locations around rail station $i$ in year $t$ and $P_{0}^{t}$ is the total population number within the linear monocentric city in year $t$.

Consequently, the stochastic user equilibrium reaches the following: no households can reduce his/her perceived disutility by unilaterally changing their residential location choices. Mathematically, the disutility for households can be expressed as

$$
\begin{aligned}
U_{i}^{t}=\min \left(\pi_{i}^{t}+\frac{r_{i}^{t}}{r o_{i}^{t}}+\frac{1}{\theta} \ln q_{i}^{t}\right) & \\
& \left(i \in\left[1, n_{s}^{t}\right], t \in[1, m]\right),
\end{aligned}
$$

where $q_{i}^{t}$ is the passenger travel demand of rail station $i$, which is a function of population density in residential location around rail station $i, \pi_{i}^{t}$ is generalized travel cost of passengers from rail station $i$ to the CBD in year $t$, and $\theta$ is sensitivity parameter in elastic passenger travel demand function $q_{i}^{t}$. With an assumption of $\varepsilon_{i}^{t}$ following independent and identical Gumbel distribution with mean value of zero, a logit-based SUE population distribution could be calculated as [13]

$$
P_{i}^{t, \text { sue }}=P_{0}^{t} \frac{\exp \left(\pi_{i}^{t}+r_{i}^{t} / r o_{i}^{t}\right)}{\sum_{i=1}^{n_{s}^{t}} \exp \left(\pi_{i}^{t}+r_{i}^{t} / r o_{i}^{t}\right)}, \quad(t \in[1, m]),
$$

where $P_{0}^{t}$ is the total population in year $t$.

The passenger travel demand of rail service is assumed to be elastic due to sensitivity to the generalized travel cost. An exponential demand function is used, shown as follows [14]:

$$
\begin{aligned}
q_{i}^{t}=P_{i}^{t} \exp \left(-\theta\left(\pi_{i}^{t}+\varepsilon_{i}^{t}\right)\right), & \\
& \left(i \in\left[1, n_{s}^{t}\right], t \in[1, m]\right),
\end{aligned}
$$

where $\theta$ is a positive constant and $\varepsilon_{i}^{t}$ is the perception error of generalized travel cost.

\section{Model Formulation}

The rail operator of rail and TOD projects is assumed to minimize the investment risk for a given required expected ROI that they are willing to earn. The investment risk could be measured by standard deviation of ROI [7]. The greater the standard deviation is, the greater the risk is. Specifically, the objective of the rail operator is to minimize standard deviation of ROI by available capital allocation. An alternative way is to examine the following investment portfolio question with the consideration of two assets: one risk-free asset which has a low ROI but no risk and another risky asset that has a higher expected ROI for a higher risk. By varying a relative proportion of the two assets, a ROI tradeoff can be selected, and correspondingly available capital can be allocated $[15,16]$.

3.1. Expected ROI Constrained Investment Risk Minimization Model. The expected ROI constrained investment risk minimization model can be formulated as follows:

$$
\begin{array}{ll}
\text { Minimize } & \sigma(\mathrm{ROI}) \\
\text { s.t. } & \beta E\left(r_{f}\right)+\alpha(1-\beta) E\left(\mathrm{ROI}_{0}\right) \\
& +(1-\beta) \sum_{i=1}^{n^{t}} \alpha_{i} E\left(\mathrm{ROI}_{i}\right)=E(\mathrm{ROI}), \\
& \beta+\alpha(1-\beta)+(1-\beta) \sum_{i=1}^{n^{t}} \alpha_{i}=1, \\
& 0 \leq \alpha \leq 1, \\
& \beta \leq 1 .
\end{array}
$$

Denote $\omega_{-1}=\beta, \omega_{0}=\alpha(1-\beta)$, and $\omega_{i}=(1-\beta) \alpha_{i}$, $\forall i \in\left[1, n^{t}\right]$. Given a mean value of $E(\mathrm{ROI})$ and $r_{f}$, since 


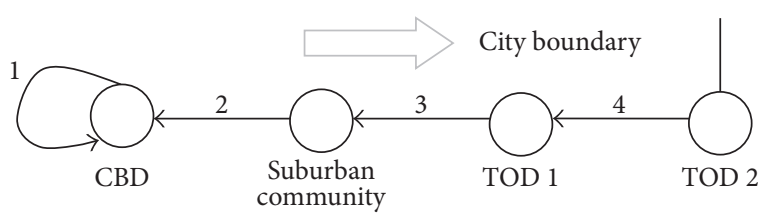

FIGURE 2: A small test network.

$\sigma(\mathrm{ROI})=\left[\sum_{i, j=0}^{n^{t}} \omega_{i} \omega_{j} \sigma\left(\mathrm{ROI}_{i}, \mathrm{ROI}_{j}\right)\right]^{1 / 2}>0$, the above formulation is equivalent to solving the following problem:

$$
\begin{aligned}
\text { Maximize } & \frac{E(\mathrm{ROI})-r_{f}}{\sigma(\mathrm{ROI})} \\
& =\frac{\sum_{i=0}^{n^{t}} \omega_{i}\left[E\left(\mathrm{ROI}_{i}\right)-E\left(r_{f}\right)\right]}{\left[\sum_{i, j=0}^{n^{t}} \omega_{i} \omega_{j} \sigma\left(\mathrm{ROI}_{i}, \mathrm{ROI}_{j}\right)\right]^{1 / 2}} \\
\text { s.t. } & \sum_{i=-1}^{n^{t}} \omega_{i}=1 .
\end{aligned}
$$

Let $v_{i}=\lambda \omega_{i}$, and then, in terms of Karush-KuhnTucker conditions, $v_{i}$ satisfies the following system of linear equations:

$$
\sum_{j=0}^{n^{t}} \sigma\left(\mathrm{ROI}_{i}, \mathrm{ROI}_{j}\right) v_{j}=E\left(\mathrm{ROI}_{i}\right)-r_{f}, \quad \forall i \in\left[0, n^{t}\right] .
$$

Finally, $\omega_{i}$ could be calculated by

$$
\omega_{i}=\frac{v_{i}}{\sum_{i=0}^{n_{s}^{t}} v_{i}}, \quad \forall i \in\left[0, n^{t}\right] .
$$

Given an expected mean value of ROI E(ROI) and riskfree asset $r_{f}$, the optimal investment proportions $\omega_{i}$ on rail and each TOD project, with respect to the objective of investment risk minimization, are unique, which is the solution of linear equations system of (19) and normalization calculation of (20) [7].

3.2. Closed-Form Solutions for Decision Variables of Rail and TOD Projects. The social welfare maximization over years for rail and TOD projects can be formulated as

$\max$

$$
\begin{aligned}
& \operatorname{SW}\left(L^{t}, n^{t}, Y_{i}^{t}\right)=\mathrm{SWR}+\mathrm{SWT} \\
& =\sum_{t=1}^{m} \sum_{i=1}^{n_{s}^{t}}\left(q_{i}^{t, \text { sue }}(f-c)\right)-L^{t} C_{r}-n_{s}^{t} C_{s}+\sum_{i=1}^{n_{s}^{t}} \frac{q_{i}^{t, \text { sue }}}{\theta} \sum_{i=1}^{n^{t}} \sum_{j=1}^{m}\left(P_{i}^{j, \text { sue }}\left(r_{i}^{j}-c_{i}\right)-Y_{i}^{j} C_{i}+\int_{0}^{P_{i}^{j}}\left(P_{i}^{j}\right)^{-1}(w) \mathrm{d} w-P_{i}^{j} r_{i}^{j}\right),
\end{aligned}
$$

where $\operatorname{SW}\left(L^{t}, n^{t}, Y_{i}^{t}\right)$ is the total social welfare over years for rail and TOD projects, and the decision variables include the rail line length $L^{t}$, TOD projects number $n^{t}$, and housing unit in each TOD project $Y_{i}^{t}\left(\forall i \in\left[1, n^{t}\right]\right)$.

The optimal rail line length, TOD projects number, and housing unit of each TOD project satisfy the following system of equations:

$$
\begin{aligned}
& \left(L^{t}\right)^{*} \\
& =\frac{\sum_{t=1}^{m} \sum_{i=1}^{n^{t}} P_{i}^{t}\left(2 r_{i}^{t}+\Delta_{i}+\Delta_{i} / \theta(f-c)-\chi_{0}-c_{i}\right)}{C_{r}} \\
& \left(n^{t}\right)^{*} \\
& =\frac{\sum_{t=1}^{m} P_{n^{t}}^{t}\left(2 r_{n^{t}}^{t}+\Delta_{n^{t}}+\Delta_{n^{t}} / \theta(f-c)-\chi_{0}-c_{n^{t}}\right)}{C_{s}} \\
& \left(Y_{i}^{t}\right)^{*}=e^{\left(b / \chi_{0} \chi_{1}\right)(1 / a) \arctan \left(\left(r_{i}^{t} / \chi_{0} \chi_{1}-1 / \chi_{1}-b / 2 \chi_{0} \chi_{1}\right) / a\right)+\kappa}
\end{aligned}
$$

where $\Delta_{i}=\left((f-c) /\left(1+\theta q_{i}^{t} \pi_{i}^{t}\right)\right) \exp \left(-\theta \pi_{i}^{t}\right), b=2 \chi_{0} \chi_{1}+\Delta_{i}+$ $\Delta_{i} / \theta(f-c)+\chi_{0}-c_{i}, c$ is a constant term determined by initial condition, and $a=\sqrt{C_{i} / \chi_{0} \chi_{1}-(b)^{2} / 4\left(\chi_{0} \chi_{1}\right)^{2}}$.
Based on (19) and (20), the optimal investment proportions under investment risk minimization equation (17a)(17e) for the optimal rail and TOD projects with respect to the objective of social welfare equation (21) are unique.

\section{Numerical Example}

A small tractable network is chosen for the test. It consists of four links, 1, 2, 3, and 4, and four residential locations, central business district (CBD), suburban community, TOD 1, and TOD 2, as shown in Figure 2. Rail exists between the CBD and the suburban community. This rail is extended from the suburban community to TOD 2. Meanwhile, TOD 1 and TOD 2 are developed by the rail operator as an indirect subsidy.

The Bureau of Public Roads (BPR) travel time function is employed to define the travel cost, shown as follows:

$$
\begin{aligned}
& E\left(\pi_{i}^{t}\right)=\mu t_{i}^{0}+\gamma t_{i}^{0}\left(0.15\left(\frac{q_{i}^{t}}{S_{i}^{t}}\right)^{4}\right), \\
& \sigma\left(\pi_{i}^{t}\right)=\frac{1}{5} E\left(\pi_{i}^{t}\right),
\end{aligned}
$$

$$
\forall i=1,2,3,4 \text {, }
$$

where $t_{i}^{0}$ is the travel time on link $i$ by rail in year $t, \mu$ is the value of time, $\gamma$ is the parameter for rail crowding, and $S_{i}^{t}$ are 
TABLE 1: The resultant mean ROI values of each candidate project with respect to different temporal and spatial CC and population growing factor.

\begin{tabular}{|c|c|c|c|c|c|c|c|c|c|c|}
\hline \multirow{2}{*}{$\begin{array}{l}E\left(\mathrm{ROI}_{i}\right) \\
(\%)\end{array}$} & \multicolumn{10}{|c|}{ Scenarios with different temporal and spatial CC } \\
\hline & Project & S1 & S2 & S3 & S4 & S5 & S6 & S7 & S8 & S9 \\
\hline \multirow{3}{*}{$E\left(\mathrm{ROI}_{i}\right)_{0.2}$} & Rail & 0.60 & 0.50 & 0.50 & 0.50 & 0.50 & 0.50 & 0.50 & 0.50 & 0.40 \\
\hline & TOD 1 & 6.50 & 6.24 & 6.20 & 6.08 & 5.84 & 6.05 & 6.39 & 6.11 & 5.80 \\
\hline & TOD 2 & 2.03 & 1.97 & 1.96 & 1.93 & 1.87 & 1.92 & 2.00 & 1.94 & 1.86 \\
\hline \multirow{3}{*}{$E\left(\mathrm{ROI}_{i}\right)_{0.4}$} & Rail & 0.60 & 0.60 & 0.50 & 0.40 & 0.50 & 0.50 & 0.60 & 0.50 & 0.50 \\
\hline & TOD 1 & 12.85 & 12.47 & 11.82 & 12.13 & 11.94 & 11.37 & 12.58 & 11.37 & 11.32 \\
\hline & TOD 2 & 3.75 & 3.90 & 3.74 & 4.05 & 3.77 & 3.63 & 3.92 & 3.63 & 3.62 \\
\hline
\end{tabular}

the link capacity of rail in year $t$. The parameters are set as $t_{1}^{0}=0.05$ (hour), $t_{2}^{0}=0.6$ (hour), $t_{3}^{0}=0.8$ (hour), $t_{4}^{0}=1.2$ (hour), $S_{i}^{t}=80000$ (persons/hour), $\mu=80$ (HK\$/hour), $\gamma=100$ (HK\$/hour), and $\varepsilon \sim N(0,6)$. The mean values of population density in each residential location in the initial year are given as follows [17]:

$$
\begin{aligned}
& E\left(P_{1}^{1}\right)=5000 \text { (persons), } \\
& E\left(P_{2}^{1}\right)=10000 \text { (persons), } \\
& E\left(P_{3}^{1}\right)=E\left(P_{4}^{1}\right)=12000 \text { (persons). }
\end{aligned}
$$

Coefficient of variation (CV) is equal to the mean divided by variance. It is assumed in this example that the $\mathrm{CV}$ of all the population is constant and set as 0.3 . The following housing rent functions are adopted for this example:

$$
\begin{aligned}
E\left(r_{i}^{t}\right) & =\chi_{0}\left(1+\chi_{1} \frac{P_{i}^{t}}{Y_{i}^{t}}\right), \\
\sigma\left(r_{i}^{t}\right) & =\frac{1}{10} E\left(r_{i}^{t}\right), \\
E\left(r o_{i}^{t}\right) & =\chi o_{0}\left(1+\chi o_{1} \frac{P_{i}^{t}}{Y o_{i}^{t}}\right), \\
\sigma\left(r o_{i}^{t}\right) & =\frac{1}{10} E\left(r o_{i}^{t}\right),
\end{aligned}
$$

where the parameters are given as $\chi_{0}=15.5(\mathrm{HK} \$ /$ day $)$, $\chi o_{0}=12\left(\mathrm{HK} \$\right.$ /day), $\chi_{1}=12, \chi o_{1}=12, Y_{1}^{1}=6500$ units, $Y_{2}^{1}=15000$ units, and $Y_{3}^{1}=Y_{4}^{1}=20000$ units. The other relevant input data of this example are the same as the notations values in the Notations.

The standard deviation of ROI without temporal and spatial covariance is also plotted in Figure 3; namely, minimal value line $\sigma(\mathrm{ROI})=0$. It is safe to conclude that investment risk is substantially underestimated without consideration of yearly variation of population densities.

Figure 3 presents the notion that the standard deviation of ROI, $\sigma(\mathrm{ROI})$, will be 0 , if no spatial and temporal covariance were considered. $\sigma(\mathrm{ROI})$ will also be 0 when the temporal covariance coefficient is 0 , whereas it is positive as spatial

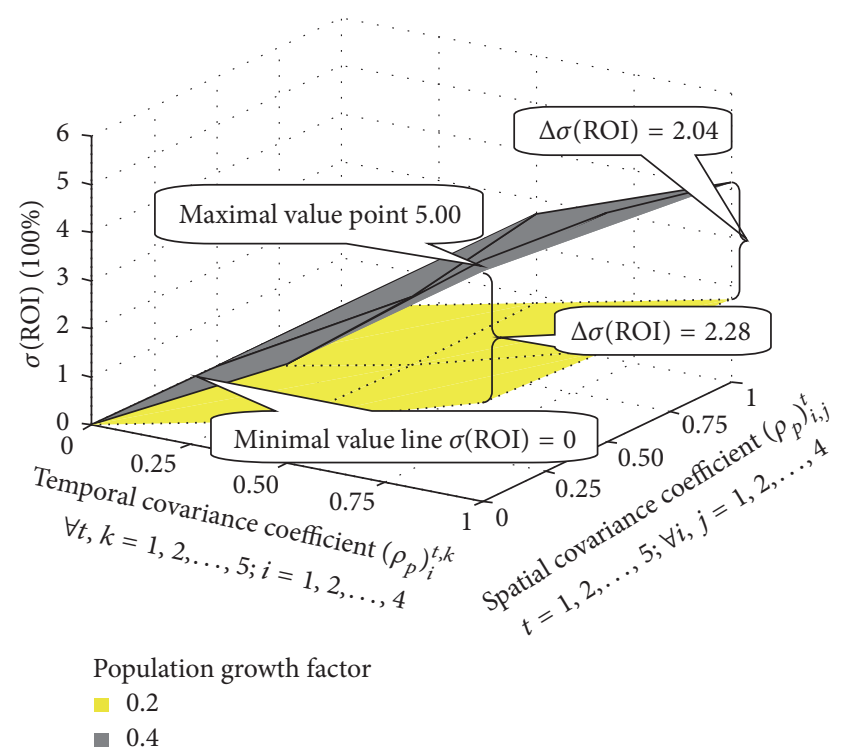

Figure 3: The standard deviation of ROI with respect to different temporal and spatial covariance coefficients and population growth factors over years.

covariance increases from 0 to $1 . \sigma(\mathrm{ROI})$ increases as the population growth factor of total population increases from 0.2 to 0.4 . The maximal value point of $\sigma(\mathrm{ROI})$ is 5.00 for population growth factor 0.4 . The difference of $\sigma(\mathrm{ROI})$ under population growth factors 0.2 and $0.4, \Delta \sigma$ (ROI), is 2.28 , with respect to temporal covariance coefficient 1 and spatial covariance coefficient 0 .

The mean ROI values of each candidate project are shown in Table 1. From this table, one can observe that $E\left(\mathrm{ROI}_{i}\right)_{0.2}$ of rail, TOD 1, and TOD 2 are higher under scenario S1 (without consideration of spatial and temporal CC) than under the other scenarios (from S2 to S9). Thus, overestimation of investment risks exists without consideration of either temporal CC or spatial CC for population growth factor 0.2 . Huge investment is required for the rail project. It could be seen that the ROI of rail is far less than the risk-free asset, while the ROIs of TOD projects are more than the risk-free asset. For example, under $\mathrm{S} 1$ with population growth factor of 
0.4 , the mean ROI value of rail is $0.6 \%$, whereas those of TOD 1 and TOD 2 are $12.85 \%$ and $3.75 \%$.

\section{Concluding Remarks}

This paper proposes an integrated model to optimize simultaneously the decision variables of rail and TOD projects over years in a linear monocentric city. This model explicitly considers the effects of the yearly variation in population density and the correlation of spatial and temporal population densities on the return on investment (ROI) of the rail and TOD projects. It is found that the ROI of rail and TOD projects may be underestimated without consideration of yearly variation in population density and correlation of spatial and temporal population densities. The TOD projects can greatly improve the financial feasibility of rail project and increase the rail project attraction for a revenue-driven rail operator.

Further research can be conducted in the following directions:

(i) In this paper, a linear monocentric city is used with only one CBD and several residential TOD locations. The city boundary is not explicitly considered. It is necessary to elaborate the city boundary so as to extend to a polycentric city model.

(ii) All households are assumed to be homogenous and only commute from residential locations to the CBD in this paper. However, previous studies have shown that income levels may dominate the residential location choice (see, e.g., $[18,19])$. Therefore, the model can be extended to incorporate the income level for determining residential locations.

(iii) The investment risk comes from yearly variation in population density and correlation of spatial and temporal population densities in this paper. However, there are also many other typical investment risks. It is worthwhile to develop more detailed models in this directions.

\section{Appendix}

$c$ : Variable operation cost for each passenger (HK\$) (5)

$c_{i}$ : Variable cost to supply housing service in TOD $i$ for each passenger ( $i$ is a positive integer, $\left.\forall i \in\left[1, n^{t}\right]\right)$ (HK\$/day) (60)

$C_{r}$ : Unit fixed construction cost of rail line (billion HK\$) (2)

$C_{s}$ : Unit fixed construction cost for each rail station (billion $\mathrm{HK} \$$ ) (0.5)

$C_{i}$ : Average fixed cost to construct each housing unit in TOD $i$ ( $i$ is a positive integer, $\left.\forall i \in\left[1, n^{t}\right]\right)$ (billion HK\$) (0.01)

$f$ : Flat fare of rail service for each passenger (HK\$) (10)
$L^{t}: \quad$ Rail line length in year $t(t$ is a positive integer, and $t \in[1, m])(\mathrm{Km})(-)$

$n^{t}: \quad$ TOD projects number in year $t(-)$

$n_{s}^{t}: \quad \quad$ Rail station number in year $t(-)$

$P_{0}^{t}$ : Total population number within the linear monocentric city in year $t$ (persons) (-)

$P_{i}^{t}$ : $\quad$ Population density around rail station $i$ in year $t\left(i\right.$ is a positive integer, $\left.\forall i \in\left[1, n_{s}^{t}\right]\right)$ (persons) (-)

$q_{i}^{t}: \quad$ Passenger travel demand of rail station $i$ in year $t$ (persons) (-)

$r_{f}: \quad$ ROI of risk-free asset (\%) (3\%)

$r_{i}^{t}: \quad$ Daily housing rent of TOD $i$ in year $t(i$ is a positive integer, $\left.\forall i \in\left[1, n^{t}\right]\right)(\mathrm{HK} \$ /$ day $)$ (-)

$Y_{i}^{t}$ : $\quad$ Housing unit in TOD project $i$ in year $t$ (HK\$/day) (-)

$Y o_{i}$ : Housing units in residential location $i$ without TOD projects in year $t(i$ is a positive integer, $\left.\forall i \in\left[1, n_{s}^{t}-n^{t}\right]\right)$ (HK\$/day) (-)

$U_{i}^{t}$ : $\quad$ Passenger's disutility for residential location around rail station $i$ in year $t(-)$

$\alpha: \quad$ Investment proportion on the rail project (一)

$\alpha_{i}: \quad$ Investment proportion on TOD project $i$ ( $i$ is a positive integer, $\left.\forall i \in\left[1, n^{t}\right]\right)(-)$

$\beta$ : $\quad$ Investment proportion on risk-free asset

$(-)$

$\pi_{i}^{t}$ : $\quad$ Generalized travel cost of passengers from rail station $i$ to the CBD in year $t(i$ is a positive integer, $\left.\forall i \in\left[1, n_{s}^{t}\right]\right)(\mathrm{HK} \$)(-)$

$\theta: \quad$ Sensitivity parameter in elastic demand function (0.01)

$\chi_{0} / \chi_{1}$ : Parameters in housing rent function for residential locations with TOD projects $(15.5 / 12)$

$\chi o_{0} / \chi o_{1}$ : Parameters in housing rent function for other residential locations without TOD projects $(12 / 12)$

$\omega_{i}$ : $\quad$ Parameter in the risk minimization model (-).

\section{Competing Interests}

The authors declare that they have no competing interests.

\section{Acknowledgments}

This study is supported by the State Key Laboratory of Rail Traffic Control and Safety (Contract no. RCS2014K005), Beijing Jiaotong University. It is also partly supported by a grant from the Research Grant Council of the Hong Kong Special Administrative Region (Project no. PolyU 5215/09E) and the National Natural Science Foundation of China (Grants nos. 61304203,71431003 , and 71571012). The authors would like to thank Professor W. H. K. Lam for his useful comments on this work. The authors are also grateful for the support of the 
Lloyd's Register Foundation, a charity that helps to protect life and property by supporting engineering-related education, public engagement, and the application of research.

\section{References}

[1] S. B. Tang and H. K. Lo, "On the financial viability of mass transit development: the case of Hong Kong," Transportation, vol. 37, no. 2, pp. 299-316, 2010.

[2] R. Cervero, "Transit-based housing in California: evidence on ridership impacts," Transport Policy, vol. 1, no. 3, pp. 174-183, 1994.

[3] M. A. White and J. B. McDaniel, The Zoning and Real Estate Implications of Transit-Oriented Development, Legal Research Digest, Transit Cooperative Research Program, Transportation Research Board, Washington, DC, USA, 1999.

[4] J. J. Lin and C. C. Gau, "A TOD planning model to review the regulation of allowable development densities around subway stations," Land Use Policy, vol. 23, no. 3, pp. 353-360, 2006.

[5] Z.-C. Li, W. H. K. Lam, S. C. Wong, and K. Choi, "Modeling the effects of integrated rail and property development on the design of rail line services in a linear monocentric city," Transportation Research Part B: Methodological, vol. 46, no. 6, pp. 710-728, 2012.

[6] D. Liu, "Modelling the effects of spatial and temporal correlation of population densities in a railway transportation corridor," European Journal of Transport and Infrastructure Research, vol. 15, no. 2, pp. 243-260, 2015.

[7] H. M. Markowitz, "Portfolio selection," The Journal of Finance, vol. 7, no. 1, pp. 77-91, 1952.

[8] Y. F. Yin, S. M. Madanat, and X.-Y. Lu, "Robust improvement schemes for road networks under demand uncertainty," European Journal of Operational Research, vol. 198, no. 2, pp. 470479, 2009.

[9] L. L. Xiao, R. H. Liu, and H. J. Huang, "Congestion behavior under uncertainty on morning commute with preferred arrival time interval," Discrete Dynamics in Nature and Society, vol. 2014, Article ID 767851, 9 pages, 2014.

[10] H. K. Lo and W. Y. Szeto, “Time-dependent transport network design under cost-recovery," Transportation Research Part B: Methodological, vol. 43, no. 1, pp. 142-158, 2009.

[11] Á. Ibeas, R. Cordera, L. Dell'Olio, and P. Coppola, "Modelling the spatial interactions between workplace and residential location," Transportation Research Part A: Policy and Practice, vol. 49, pp. 110-122, 2013.

[12] H. W. Ho and S. C. Wong, "Housing allocation problem in a continuum transportation system," Transportmetrica, vol. 3, no. 1, pp. 21-39, 2007.

[13] Y. Sheffi, Urban Transportation Networks: Equilibrium Analysis with Mathematical Programming Methods, Prentice-Hall, Englewood Cliffs, NJ, USA, 1985.

[14] Z.-C. Li, W. H. K. Lam, S. C. Wong, and A. Sumalee, "Design of a rail transit line for profit maximization in a linear transportation corridor," Transportation Research Part E: Logistics and Transportation Review, vol. 48, no. 1, pp. 50-70, 2012.

[15] J. Siskos and C. Zopounidis, "The evaluation criteria of the venture capital investment activity: an interactive assessment," European Journal of Operational Research, vol. 31, no. 3, pp. 304313, 1987.

[16] C. Zopounidis, "Multicriteria decision aid in financial management," European Journal of Operational Research, vol. 119, no. 2, pp. 404-415, 1999.
[17] W. H. K. Lam, H. Shao, and A. Sumalee, "Modeling impacts of adverse weather conditions on a road network with uncertainties in demand and supply," Transportation Research Part B: Methodological, vol. 42, no. 10, pp. 890-910, 2008.

[18] J. Hartwick, U. Schweizer, and P. Varaiya, "Comparative statics of a residential economy with several classes," Journal of Economic Theory, vol. 13, no. 3, pp. 396-413, 1976.

[19] Y. Kwon, "The effect of a change in wages on welfare in a twoclass monocentric city," Journal of Regional Science, vol. 43, no. 1, pp. 63-72, 2003. 


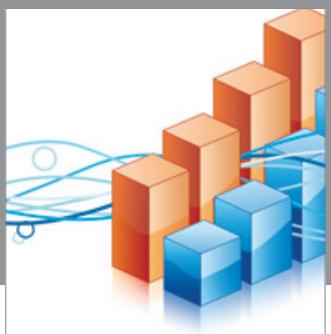

Advances in

Operations Research

vatem alat4

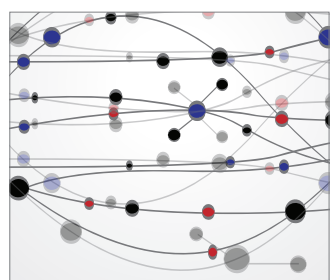

\section{The Scientific} World Journal
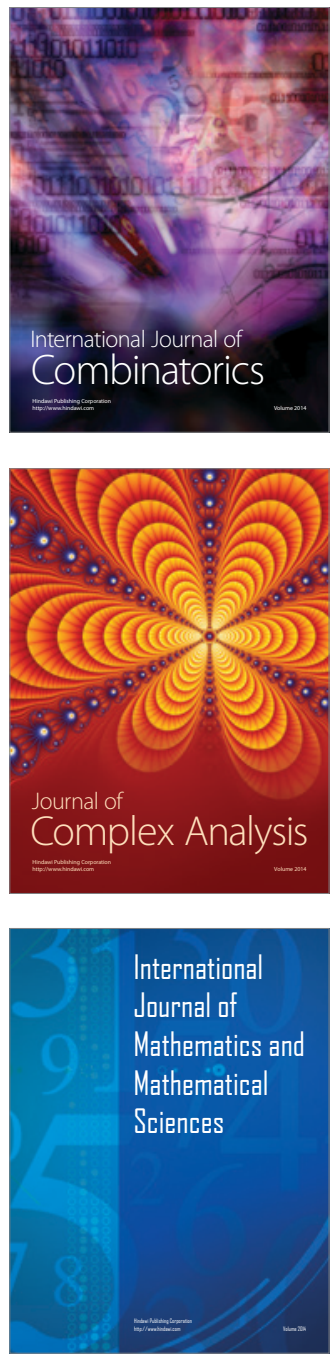
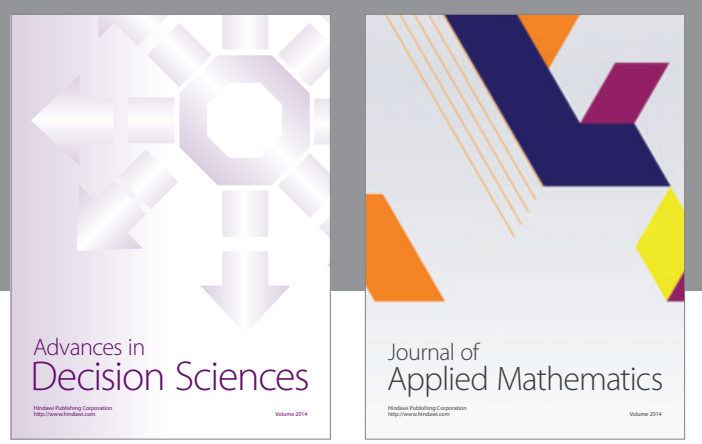

Algebra

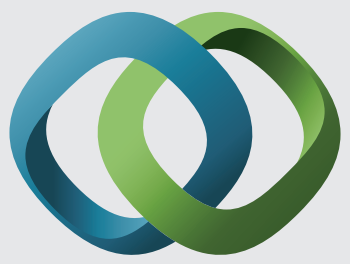

\section{Hindawi}

Submit your manuscripts at

http://www.hindawi.com
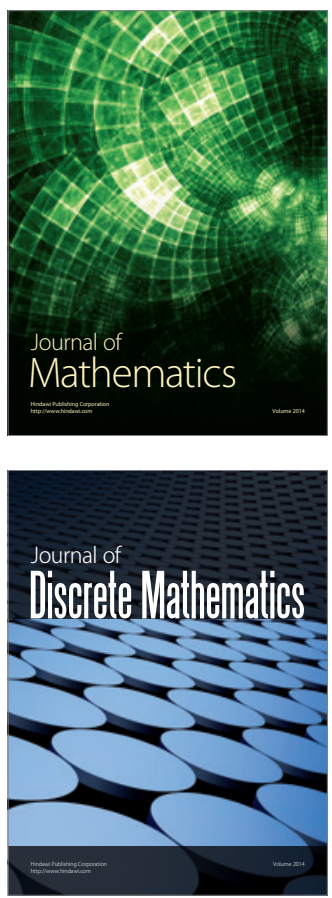

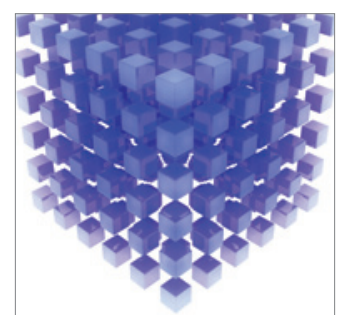

Mathematical Problems in Engineering
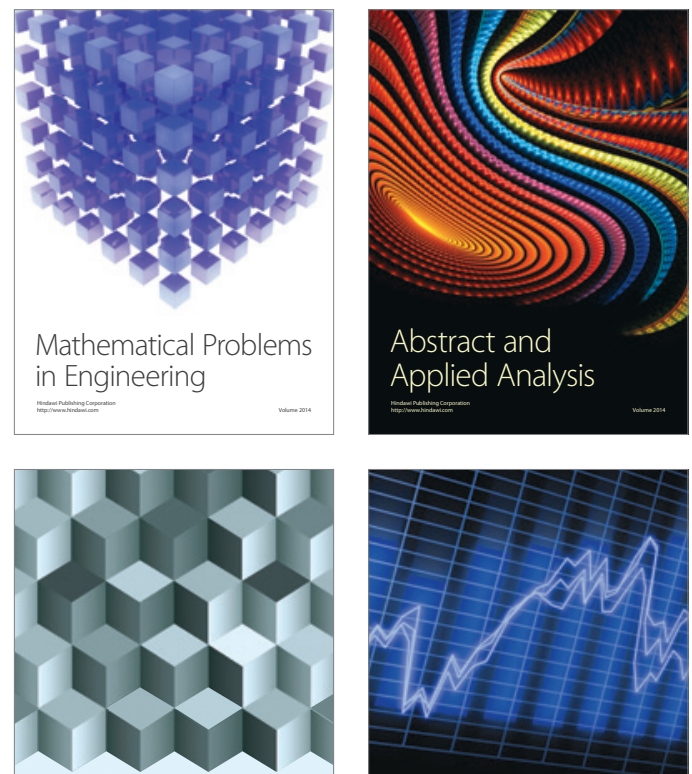

Journal of

Function Spaces

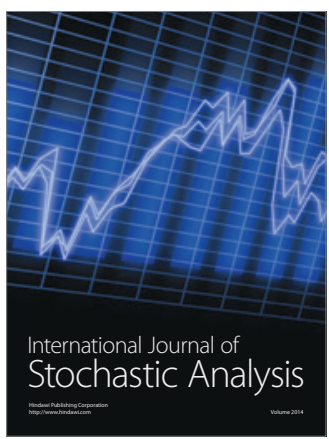

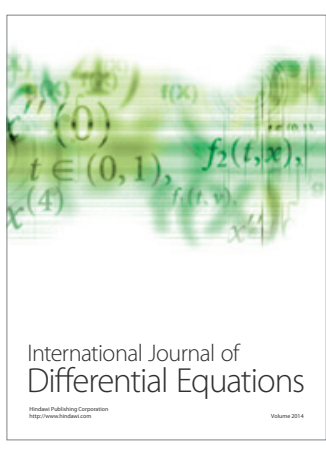
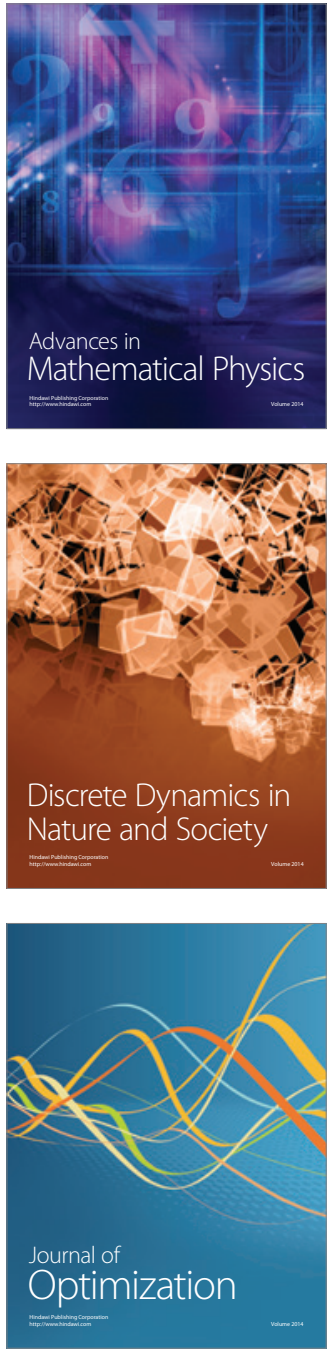